\title{
Acta
Biochimica
Polonica
}

Vol. 45 No. $3 / 1998$

$745-754$

QUARTERLY

\section{A cell-free yellow lupin extract containing activities of pseudouridine 35 and 55 synthases ${ }^{\oplus}$}

\author{
Joanna Pieńkowska ${ }^{1}$, Jan Wrzesiński ${ }^{2}$ and Zofia Szweykowska-Kulińska ${ }^{1 凶}$ \\ ${ }^{1}$ Department of Gene Expression, Poznań University, Międzychodzka 5, 60-371 Poznań, Poland, \\ ${ }^{2}$ Institute of Bioorganic Chemistry, Polish Academy of Sciences, Z. Noskowskiego 12/14, \\ 61-704 Poznań, Poland
}

Received: 13 May, 1998

Key words: pseudouridine synthases, $\mathrm{RRNA}^{\mathrm{Tyr}}$, yellow lupin extract

\begin{abstract}
Plant cytoplasmic tyrosine tRNA was pseudouridylated at three different positions: 35,39 and 55 . These pseudouridines were introduced by three different enzymes pseudouridine synthases. Variants of the Arabidopsis thaliana pre-tRNA ${ }^{\mathrm{Tyr}}$ were constructed that allow to monitor specifically pseudouridylation at different nucleotide positions. Using such RNAs to assay pseudouridine synthesis we have prepared an extract from Lupinus luteus cv. Ventus seeds containing activities of at least $\Psi 35$ and $\Psi 55$ synthases. This is the first report describing the preparation of the lupin seed extract that specifically modifies plant pre-tRNA ${ }^{\mathrm{Ty} r}$ transcribed by T7 RNA polymerase. U35 is converted to $\Psi 35$ only in an intron-dependent manner, while pseudouridylation of U55 is insensitive to the presence or absence of an intron.
\end{abstract}

RNA maturation is a complex multistep process in which the primary transcript of a gene serves as a substrate for a large number of different enzymes. Cytoplasmic mature transfer RNA appears as a product of different enzyme activities that are involved in the maturation of pre-tRNA $5^{\prime}$ - and 3 '-ends, splicing and nucleoside modifications. While maturation of the 5 '- and 3 '-ends takes place in the nucleus [1] and the splicing occurs at the nuclear enve- lope [2], nucleoside modifications are introduced in different compartments of the cell: in the nucleus, in the cytoplasm and in organelles [3]. Several modified nucleosides in tRNA molecules are introduced only at defined steps of the tRNA maturation pathway. Some of them appear only before intron excision (in the nucleus) $[4,5]$, other only after intron removal (in the cytoplasm or in the organelles) [6]. There are, however, also some

\footnotetext{
${ }^{{ }^{T} \text { This work was supported by the Polish Committee for Scientific Research project No. } 6 \text { P04A 00312 and }}$ the A. Mickiewicz University Faculty of Biology grant.

${ }^{\circledR}$ Corresponding author: Zofia Szweykowska-Kulińska; tel. (48 61) 8615511 ext. 35; fax: (48 60) 8615596 ; e-mail: zofszwey@main.amu.edu.pl
}

Abbreviations: bp, base pair(s); DTT, dithiothreitol; nt, nucleotide(s). 
modified nucleosides the appearance of which is insensitive to the presence or absence of an intron [7]. Their introduction can occur in the nucleus (e.g. yeast $N^{2}, N^{2}$-dimethylguanosine [3]) or in the cytoplasm (queuosine [3]). An example of a modified nucleoside that is introduced at the stage of intron-containing tRNA precursor is pseudouridine, found in the mid-

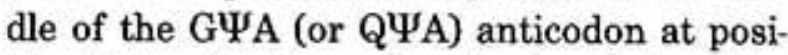
tion 35 in all eukaryotic cytoplasmic tyrosine tRNAs studied so far [4]. An example of a modified nucleoside that is introduced only after intron excision is $\Psi 32$ in yeast cytoplasmic tRNA ${ }^{\text {Leu }}$ (CAA) [7]. Pseudouridine 55 in the TYC arm is an example of a modified nucleoside introduced into different pre-tRNAs in yeast and vertebrates in a manner insensitive to the presence of an intron [8]. While data that describe the tRNA maturation process involving nucleoside modification in yeast and vertebrates accumulate, the analogous processes that take place in plants remain almost unknown. A major handicap for studying plant tRNA maturation are the difficulties with the preparation of homologous in vitro transcription system. Last year the group of Sugiura reported the preparation of the first in vitro polymerase III plant-specific nuclear extract from tobacco cultured cells [9]. However, T7 RNA polymerase in vitro transcription assay could serve as a powerful tool since it can produce large amounts of a plant tRNA precursor that can be used in further observations on the maturation process [10]. A cell-free pre-tRNA processing and splicing system from wheat germ has been established [11].

Here we describe the preparation of a lupin seed extract that specifically modifies plant pre-tRNA $^{\text {Tyr }}$ transcribed by T7 RNA polymerase, giving pre-tRNA ${ }^{\text {Tyr }}$ molecules almost fully pseudouridylated at the 35 th and the 55 th position. To our knowledge, this is the first report describing the preparation of such extract from lupin seeds. Furthermore, pseudouridylation that takes place in the middle position of the plant pre-tRNA ${ }^{\text {Tyr }}$ anticodon is introduced only at the stage of an introncontaining precursor while the conversion of U55 to $\Psi 55$ in the T $\Psi \mathrm{C}$ arm is insensitive to the presence or absence of an intron, as described in the case of yeast and vertebrates.

\section{MATERIALS AND METHODS}

\section{Enzymes and reagents}

RNase T2 was obtained from Calbiochem or Sigma, $\left[\alpha-{ }^{32}\right.$ P]NTPs (spec. act. $29.6 \mathrm{TBq} /$ mmol), $\left[\alpha-{ }^{35}\right.$ S]dATP (spec. act. $>37 \mathrm{TBq} /$ mmol) and $\left[5-{ }^{3} \mathrm{H}\right] U T P$ (spec. act. $492 \mathrm{Gbq}$ / mmol) were from Amersham (U.K.), T7 DNA polymerase sequencing kit from Pharmacia, and Muta-gene site-directed mutagenesis kit from Bio-Rad. T7 RNA transcription was carried out using a T7 RNA transcription kit from Promega. Restriction enzymes, Taq DNA polymerase and all other enzymes were from Boehringer Mannheim. Other reagents were from USB. Yellow lupin seeds cv.Ventus were obtained from the Plant Breeding Station in Wierzonka (Poland).

\section{Preparation of yellow lupin S-23 extracts}

Extract I. Extract I was prepared according to Stange \& Beier [11] with some modifications: $10 \mathrm{~g}$ of yellow lupin seed meal was ground with $10 \mathrm{~g}$ of sea sand in a pre-cooled mortar until a fine powder was obtained. Then $30 \mathrm{ml}$ of extraction buffer (10 mM Tris/acetate, $\mathrm{pH} 7.6,3 \mathrm{mM} \mathrm{Mg}(\mathrm{OAc})_{2}, 50 \mathrm{mM} \mathrm{KOAc}, 1$ $\mathrm{mM}$ dithiothreitol (DTT)) was added stepwise and grinding was continued at $4^{\circ} \mathrm{C}$ until a smooth paste was obtained. The extract was centrifuged twice for $10 \mathrm{~min}$ at $23000 \times g$ and the precipitate discarded. The supernatant (crude extract) was fractionated with streptomycin sulfate. The supernatant was brought to $3 \%$ saturation by adding $20 \%$ stock of streptomycin sulfate and mixed for $30 \mathrm{~min}$. The mixture was centrifuged at $13000 \times g$ for 15 $\min$. The supernatant was collected and the 
precipitate discarded. Glycerol was added to the collected supernatant to a concentration of $10 \%(\mathrm{v} / \mathrm{v})$. Then the supernatant fraction was dialysed for $2 \mathrm{~h}$ against 100 volumes of a buffer containing $20 \mathrm{mM}$ Tris/ $\mathrm{HCl}, \mathrm{pH} 8.0$, $150 \mathrm{mM} \mathrm{NaCl}, 0.1 \mathrm{mM}$ EDTA, $5 \mathrm{mM} 2$ mercaptoethanol, $10 \%$ glycerol. All the operations were carried out at $4^{\circ} \mathrm{C}$.

Extract $\boldsymbol{H}$. Extract II was prepared according to Guranowski \& Pawełkiewicz [12] with some modifications: $10 \mathrm{~g}$ of yellow lupin seed meal was ground with $10 \mathrm{~g}$ of sea sand in a pre-cooled mortar until a fine powder was obtained. Then $30 \mathrm{ml}$ of extraction buffer (10 $\mathrm{mM}$ potassium phosphate buffer, $\mathrm{pH} 6.8$, containing $1 \mathrm{mM}$ 2-mercaptoethanol, $0.1 \mathrm{mM}$ EDTA and $10 \%(v / v)$ glycerol) was added stepwise and grinding was continued at $4^{\circ} \mathrm{C}$ until a

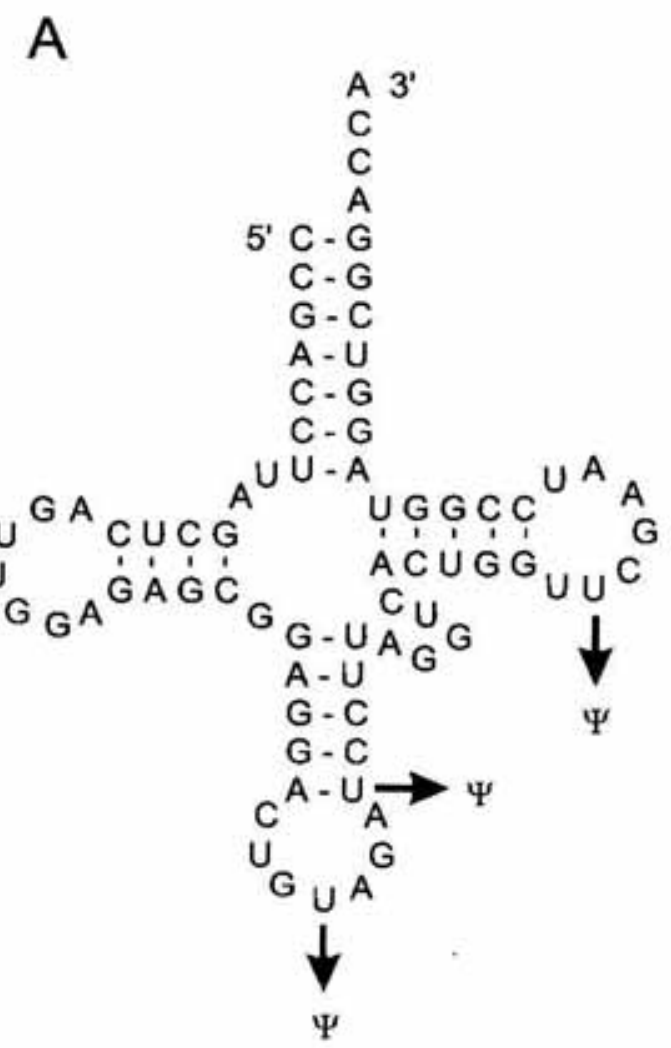

smooth paste was obtained. The extract was centrifuged twice for $10 \mathrm{~min}$ at $23000 \times \mathrm{g}$ and the precipitate discarded. Then the supernatant fraction was dialysed for $20 \mathrm{~h}$ against 100 volumes of extraction buffer. The dialysate was clarified by low speed centrifugation and the supernatant, designated the S-23 extract, was stored at $4^{\circ} \mathrm{C}$. All the operations were carried out at $4^{\circ} \mathrm{C}$.

Construction of Arabidopsis thaliana tRNA ${ }^{\mathrm{Tyr}}$ gene derivatives

The A. thaliana tRNA ${ }^{\text {Tyr }}$ gene pATY2T7 containing a $12 \mathrm{bp}$ intron was mutagenized using the method of Kunkel et al. [13]. The mutations were always confirmed by DNA sequencing according to Hattori \& Sakaki [14]. Two

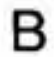

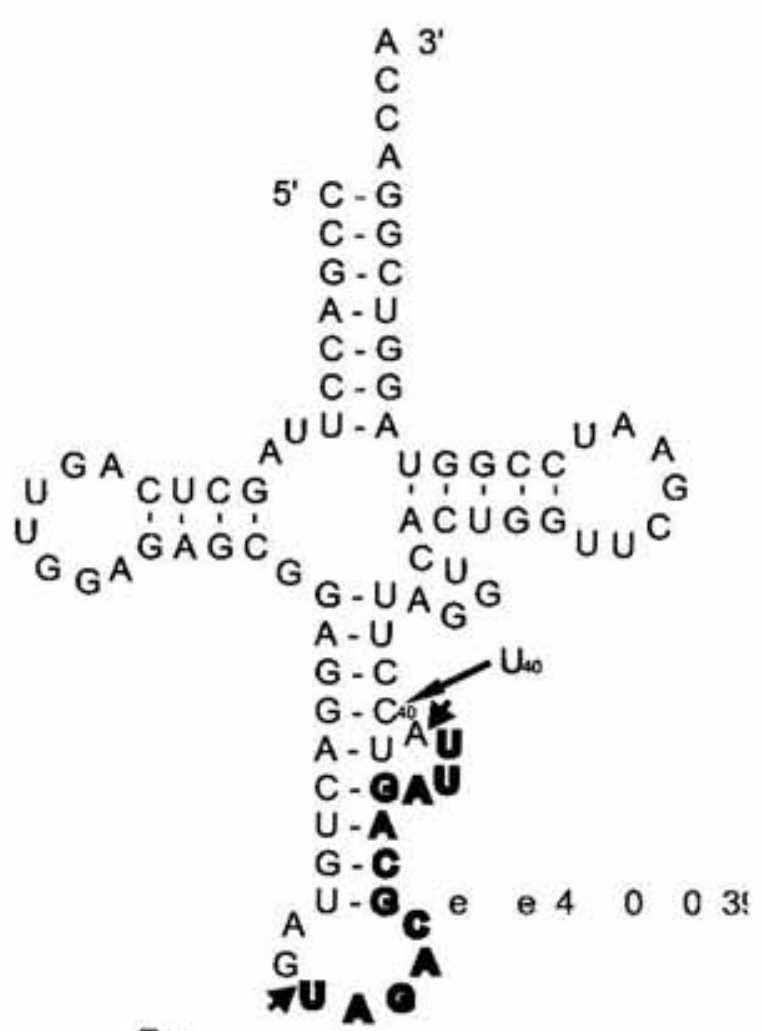

Figure1. Cloverleaf structures of unmodified A. thaliana tRNA ${ }^{\mathrm{Tyr}}$ and its primary, intron-containing transcript.

(A) A. thaliana unmodified tRNA ${ }^{\text {Tyr }}$. Pseudouridylated positions in the mature tRNA are marked. (B) pre-tRNA ${ }^{\text {Tyr }}$ containing an intron. Long arrow shows the variant of pre-tRNA ${ }^{\mathrm{Tr}}$ in which $\mathrm{C} 40$ has been substituted by $\mathrm{U} 40$. Short arrows point to the splicing-sites and the intron is shown in bold letters. The pre-tRNA ${ }^{\text {Tyr }}$ variant deprived of the intron represents the cloverleaf structure identical with the structure shown in (A). 
mutants of tRNA ${ }^{\text {Tyr }}$ gene were constructed: pATY2T7U40 - in which $\mathrm{C} 40$ was replaced by $\mathrm{U} 40$, and pATY2T $7 \Delta \mathrm{I}-$ in which a $12 \mathrm{nt}$ long intron was deleted (Fig. 1). Both mutants and the wild type $A$. thaliana $\mathrm{tRNA}^{\mathrm{Tyr}}$ gene were inserted under T7 RNA polymerase promoter and terminated by $B s t \mathrm{NI}$ restriction site using the PCR technique as described in [10].

\section{T7 RNA transcription of pre-tRNA ${ }^{\text {Tyr }}$} substrates using $\left[5-{ }^{3} \mathrm{H}\right] U T \mathrm{~T},\left[\alpha-{ }^{32}\right.$ P]ATP, $\left[\alpha-{ }^{32}\right.$ P]UTP or $\left[\alpha-{ }^{32}\right.$ P]CTP

Plasmids carrying the tRNA ${ }^{\mathrm{Tyr}}$ gene or its variants were digested with $\mathrm{MvaI}$ (an isoschizomer of BstNI) before transcription.

\section{$\left[{ }^{3} \mathrm{H}\right]$ RNA transcription}

Transcription was performed in $20 \mathrm{mM}$ Tris/ $\mathrm{HCl}, \mathrm{pH} 7.8,20 \mathrm{mM} \mathrm{MgCl}_{2}, 40 \mathrm{mM} \mathrm{NaCl}$, $4 \mathrm{mM}$ spermidine, $10 \mathrm{mM}$ DTT, $2 \mathrm{mM}$ each ATP, CTP, GTP, 1.5 mM UTP, 40 nM linearized plasmid, 500 units $/ \mathrm{ml}$ T7 RNA polymerase, and $200 \mu \mathrm{Ci} / \mathrm{ml}$ of $\left[5^{-3} \mathrm{H}\right] \mathrm{UTP}$ at $37^{\circ} \mathrm{C}$ for $8-10 \mathrm{~h}$.

\section{$\left[{ }^{32}\right.$ P]RNA transcription}

tRNA ${ }^{T y r}$ labelled with [ $\alpha-{ }^{32}$ P]ATP: transcription was performed in the T7 RNA polymerase buffer, $10 \mathrm{mM}$ DTT, 1 unit/ $\mu \mathrm{l}$ Rnasin, $660 \mu \mathrm{M}$ each CTP, GTP, UTP, $44.4 \mu \mathrm{M}$ ATP, $0.1 \mu \mathrm{g} / \mu \mathrm{l}$ linearized plasmid, $2.5 \mu \mathrm{Ci} / \mathrm{ml}$ of $\left[\alpha-{ }^{32} \mathrm{P}\right] \mathrm{ATP}$ and 1 unit/ $\mu \mathrm{l}$ T7 RNA polymerase at $37^{\circ} \mathrm{C}$ for $1.5 \mathrm{~h}$.

tRNA ${ }^{T y}$ labelled with [ $\alpha{ }^{32}$ P]UTP: transcription was performed in the T7 RNA polymerase buffer, $10 \mathrm{mM}$ DTT, 1 unit/ $\mu 1$ Rna$\sin , 0.5 \mathrm{mM}$ each ATP, CTP, GTP, $120 \mu \mathrm{M}$ UTP, $0.1 \mu \mathrm{g} / \mu \mathrm{l}$ linearized plasmid, $5 \mu \mathrm{Ci} / \mathrm{ml}$ of $\left[\alpha-{ }^{32}\right.$ P]UTP and 1 unit $/ \mu \mathrm{l}$ T7 RNA polymerase at $37^{\circ} \mathrm{C}$ for $1.5 \mathrm{~h}$.

tRNA ${ }^{\text {Tyr }}$ labelled with $\left[\alpha-{ }^{32}\right.$ P]CTP: transcription was performed in the T7 RNA polymerase buffer, $10 \mathrm{mM}$ DTT, 1 unit/ $\mu$ l Rnasin, $0.5 \mathrm{mM}$ each ATP, GTP, UTP, $12 \mu \mathrm{M}$ CTP,
$0.1 \mu \mathrm{g} / \mu \mathrm{l}$ linearized plasmid, $2.5 \mu \mathrm{Ci} / \mathrm{ml}$ of $[\alpha$ -

${ }^{32} \mathrm{PJCTP}$ and 1 unit/ $\mu \mathrm{l}$ T7 RNA polymerase at $37^{\circ} \mathrm{C}$ for $1.5 \mathrm{~h}$.

All RNA samples were purified by phenol/chloroform extraction, ethanol precipitation and were further purified on $10 \%$ PAGE/8 M urea.

\section{In vitro pseudouridine formation assay}

Reactions with $\left[5-{ }^{3} \mathrm{H}\right] \mathrm{U}$ tRNA ${ }^{\text {Tyr }}$ were carried out in $80 \mu \mathrm{l}$ reaction mixture containing $50 \mathrm{mM}$ Tris/HCl, pH $7.8,10 \mathrm{mM} \mathrm{NH}_{4} \mathrm{Cl}, 5$ mM DTT, $10 \mathrm{mM} \mathrm{MgCl} 2,10-15$ pmol of [5$\left.{ }^{3} \mathrm{H}\right] \mathrm{U}$ tRNA ${ }^{\text {Tyr }}$ transcripts and $20 \mu \mathrm{l}$ of S-23 extract. Incubation was at $37^{\circ} \mathrm{C}$ for $1.5 \mathrm{~h}$. Reactions were stopped by addition of $95 \mu \mathrm{l}$ of reaction mixtures to $1.0 \mathrm{ml}$ of $12 \%$ active charcoal suspended in $0.1 \mathrm{M} \mathrm{HCl}$. Samples were stirred and allowed to stand at room temperature for $5 \mathrm{~min}$, then centrifuged to remove the charcoal; the supernatant was passed through a Millex-Gp filter assembly $(0.22 \mu \mathrm{m})$. Usually a $0.5 \mathrm{ml}$ sample was counted [15]. One unit of activity is the amount of enzyme catalysing the release of $1 \mathrm{pmol}$ of ${ }^{3} \mathrm{H}$ to the supernatant in $30 \mathrm{~min}$ at $37^{\circ} \mathrm{C}$.

In vitro pseudouridine formation assay for ${ }^{32}$ P-labelled pre-tRNAs was carried out as described above for $\left[5^{3} \mathrm{H}\right] \mathrm{U}$ tRNA ${ }^{\mathrm{Tyr}} .{ }^{32} \mathrm{P}$ labelled RNA products were purified by phenol/chloroform extraction, ethanol precipitation and further purified on $10 \%$ PAGE/ $8 \mathrm{M}$ urea.

Quantification of pseudouridine in the ${ }^{32} \mathrm{P}$ labelled tRNA samples

${ }^{32}$ P-labelled (100000 c.p.m.) RNAs, obtained as described above, were digested with 0.5 units of RNase T2 for at least $5 \mathrm{~h}$ at $37^{\circ} \mathrm{C}$ in 10 $\mu \mathrm{l}$ of $5 \mathrm{mM}$ ammonium acetate, $\mathrm{pH}$ 4.6. The labelled nucleotides were identified by twodimensional chromatographic analysis on cellulose thin-layer plates as described by Grosjean et al. [6]. The efficiency of pseudouridine modification was measured by cutting out the 
labelled spots from the TLC plates and counting the radioactivity by the liquid scintillation techniques. Taking into account the amount of label in each of the nucleotide spots (AMP, UMP, GMP, CMP and/or $\Psi \mathrm{MP}$ ) and knowing the relative number of labelled nucleotides per RNA substrate, the number of moles of each or both pseudouridines per mole of pretRNA was calculated.

\section{RESULTS}

\section{Synthesis of unmodified tRNA ${ }^{\text {Tyr }}$ variants}

The biosynthesis of $\Psi$ takes place at the polynucleotide level and involves an intramolecular rearrangement of uridine. Examination of the structure of $\Psi$ suggests that it is chemically formed from $U$ by cleavage of the carbon-nitrogen glycosyl bond, followed by rotation of the uracil base and then reattachment at $C^{5}$ to yield $\Psi$. Plant cytoplasmic tyrosine tRNA is pseudouridylated at three different positions: 35,39 and 55 (Fig. 1). The pseudouridines are introduced most probably by three different enzymes - pseudouridine synthases. Variants of the tRNA substrate were constructed that allowed us to monitor specifically pseudouridylation at different nucleotide positions (Fig. 1). Using such RNAs to assay pseudouridine synthesis, enzymes producing this nucleoside could be identified and purified from Lupinus luteus extract. The wild type tyrosine tRNA containing an intron should be pseudouridylated at three positions: in the middle position of the anticodon (35th

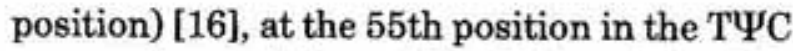
arm and, possibly, at the 39th position [3]. The mutant tRNA ${ }^{\mathrm{Tyr}}$ molecule derived from pATY2T7U40 template should contain $\Psi 35$, $\Psi 55$ and possibly $\Psi 39$. The mutant of $\mathrm{tRNA}^{\mathrm{Tyr}}$ molecule without an intron should be modified at two positions: 39th and 55th. Whether $\Psi 39$ is introduced also at the stage of the intron-containing molecule remains unclear [3]. These calculations were based on the previous structural studies carried out in our laboratory and by others (for review see [3]).

\section{Pseudouridylation of tRNA ${ }^{\mathrm{Tyr}}$ variants us- ing lupin S-23 extracts}

Yellow lupin seed S-23 extracts were prepared to test the activities of pseudouridine synthase as described in Materials and Methods. We tested two different protocols for plant extract preparation from seeds. Our attempts to prepare extracts containing active pseudouridine synthases from lupin seedlings were unsuccessful. Most probably the level of proteases, despite the large amounts of different protease-inhibitors used, was too high.

Usually extracts from yellow lupin seeds contained $10-15 \mathrm{mg}$ of protein $/ \mathrm{ml}$ as measured using the Bradford technique. Preliminary tests for $\Psi$ conversion using wild type pretRNA ${ }^{\text {Tyr }}$ labelled with $\left[5-{ }^{3} \mathrm{H}\right] \mathrm{UTP}$ as a substrate were carried out and the amount of tritium released was calculated. When the different RNA substrates were incubated with a lupin seed extract they all released tritium (Table 1).

Table 1. Plasmids and corresponding RNA transcripts

\begin{tabular}{|c|c|c|c|}
\hline Plasmid & $\begin{array}{l}\text { Nucleosides altered in } \\
\text { tRNA }^{\text {Tyr }} \text { gene }\end{array}$ & $\begin{array}{l}\text { Potential sites of } \Psi \\
\text { formation }\end{array}$ & $\begin{array}{l}\text { Release of tritium from } \\
\text { RNA incubated with lupin } \\
\text { seed extracts }\end{array}$ \\
\hline pATY2T7 & none, wild type & U35, U39(?)*, U55 & + \\
\hline pATY2T7АI & intron deleted & U39, U55 & + \\
\hline pATY2T7U40 & $\mathrm{C} 40 \rightarrow \mathrm{U} 40$ & U55 U35, U39(?)* & + \\
\hline
\end{tabular}

-The asterisk points to the discrepancies that exist for formation of $\Psi 39$ which was found to be negatively intron-dependent for tobacco tRNA ${ }^{\text {Tyr }}$ [11] and intron-insensitive in several other cases [3]. 
The finding that these RNAs release tritium indicates that they may be used to monitor specifically pseudouridylations at particular positions. The specific activity of pseudouridine synthases was measured using [5${ }^{3} \mathrm{H}$ ]U-pre-tRNA ${ }^{\mathrm{Tyr}}$ containing an intron giving 0.6 units $/ \mu \mathrm{l}$ of extract. Although it was not known at the time whether we monitor $\Psi 35$, $\Psi 39$ or $\Psi 55$ formation, subsequent analysis proved that the isolated extracts contained only $\Psi 35$ and $\Psi 55$ pseudouridine synthase activities. All reactions were carried out using Extract I and Extract II. Both exhibited tritium release activity. For further experiments we decided to use Extract I because of simplicity of its preparation.

Identification of pseudouridylated positions in pre-tRNA ${ }^{\text {Tyr }}$ transcripts

The formation of $\Psi 35$ can be followed by labelling the synthesised pre-tRNA ${ }^{\text {Tyr }}$ containing an intron with $\left[\alpha-{ }^{32} \mathrm{P}\right] \mathrm{ATP}$ and subsequent hydrolysis by RNase T2. The labelled phosphate is transferred from the $5^{\prime}$ positions of the adenosines to the $3^{\prime}$ positions of the nearest neighbour. Under these conditions $\Psi 35$ is labelled, but not the other two pseudouridines present at positions 39 and 55 in plant tRNA ${ }^{\text {Tyr }}$ which are followed by a cytidine. The formation of $\Psi 55$ and $\Psi 39$ can be followed by labelling the synthesised pre-tRNA ${ }^{\text {Tyr }}$ with $[\alpha$ ${ }^{32}$ P]CTP. Since both: U55 and U39 will be visible after RNase T2 digestion, a mutant of the intron-containing tRNA $^{\text {Tyr }}$ molecule was constructed, in which $\mathrm{C} 40$ that immediately follows U39 to be pseudouridylated, was changed to U40. In this case labelling of pretRNA ${ }^{\text {Tyr }}$ with $\left[\alpha_{-}{ }^{32} \mathrm{P}\right] \mathrm{CTP}$ will visualise $\Psi 55$ while labelling with $\left[\alpha-{ }^{32}\right.$ P $] U T P-\Psi 39$. The pretRNA $^{\text {Tyr }}$ without an intron labelled with [ $\alpha$ $\left.{ }^{32} \mathrm{P}\right] \mathrm{CTP}$ should show us the presence of $\Psi 55$ and $\Psi 39$.

${ }^{32} \mathrm{P}$-labelled pre-tRNAs were incubated in lupin seed Extract I under conditions described in Materials and Methods. Table 2 shows the results of identification of pseudouridylated positions in different pre-tRNA ${ }^{\text {Tyr }}$ substrates and efficiency of the reactions.

Pseudouridine 35 is introduced efficiently into the wild-type pre-tRNA ${ }^{\text {Tyr }}$ containing an intron, while its introduction is inhibited in the case of an intron-less pre-tRNA ${ }^{\text {Tyr }}$ substrate (Fig. 2). Although it was long known, that in the case of yeast, vertebrates and insects, the conversion of U35 to $\Psi 35$ absolutely requires the presence of an intron in the pretRNA $^{\text {Tyr }}$, here for the first time, it is shown clearly, that this is also true for plant pre$\mathrm{tRNA}^{\mathrm{Tyr}}$ and plant pseudouridine $35 \mathrm{syn}$ thase.

Analysis of pre-tRNA ${ }^{\text {Tyr }}$ mutant $\mathrm{C} 40 \rightarrow \mathrm{U} 40$ labelled with UTP revealed no pseudouridine at the 39th position (not shown). Furthermore, the same molecule when labelled with $\left[\alpha-{ }^{32} \mathrm{P}\right] \mathrm{CTP}$ was fully modified $(100 \%$ efficiency) at the 55 th position (Fig. $3 \mathrm{~A}$ ). In the case of wild type intron-containing pretRNA ${ }^{\text {Tyr }}$ labelled with $\left[\alpha-{ }^{32} \mathrm{P}\right] \mathrm{CTP}$ we never obtained the efficiency of pseudouridylation higher than 1 mole of $\Psi$ per one mole of pretRNA $^{\text {Tyr }}$ suggesting that there is no $\Psi 39$ syn-

Table 2. Efficiency of pseudouridine 35 and $\mathbf{5 5}$ modification in lupin seed Extract I

\begin{tabular}{lllcc}
\hline Plasmid & $\begin{array}{c}\text { Nucleosides altered } \\
\text { in tRNA }{ }^{\text {Tyr }} \text { gene }\end{array}$ & Labelling & Sites of $\Psi$ formation & $\begin{array}{l}\Psi \text { mole/mole } \\
\text { pre-tRNA }\end{array}$ \\
\hline pATY2T7 & none, wild type & {$\left[\alpha-{ }^{32}\right.$ P]ATP } & $\Psi 35$ & 0.8 \\
pATY2T7 & none, wild type & {$\left[\alpha-{ }^{32}\right.$ PICTP } & $\Psi 55$ & 1.0 \\
pATY2T7 $\Delta \mathrm{I}$ & intron deleted & {$\left[\alpha-{ }^{32} \mathrm{P}\right] \mathrm{ATP}$} & $\Psi 35$ & 0.0 \\
pATY2T7 $\triangle \mathrm{I}$ & intron deleted & {$\left[\alpha{ }^{32} \mathrm{P}\right] \mathrm{CTP}$} & $\Psi 55$ & 1.0 \\
pATY2T7U40 & $\mathrm{C} 40 \rightarrow \mathrm{U} 40$ & {$\left[\alpha-{ }^{32} \mathrm{P}\right] \mathrm{CTP}$} & $\Psi 55$ & 1.0 \\
pATY2T7U40 & $\mathrm{C} 40 \rightarrow \mathrm{U} 40$ & {$\left[\alpha-{ }^{32} \mathrm{P}\right] \mathrm{UTP}$} & $\Psi 39$ & 0.0 \\
\hline
\end{tabular}


A

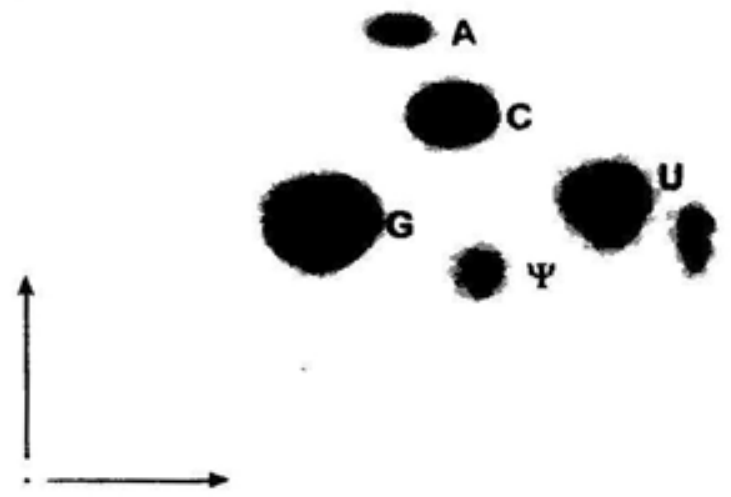

B

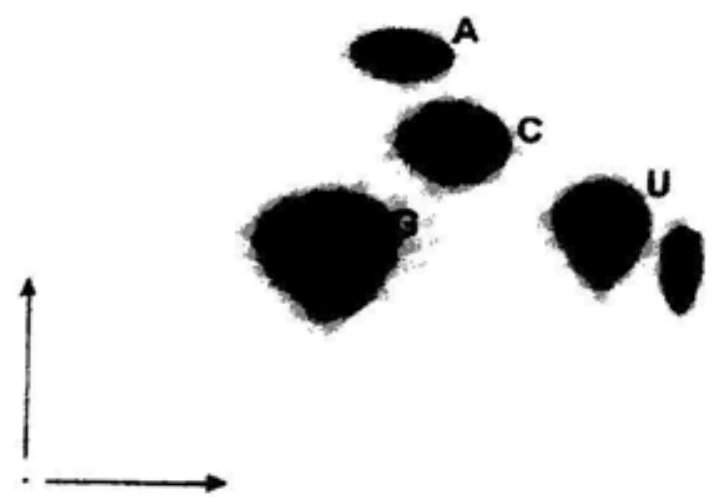

Figure 2. Pseudouridine 35 synthesis in yellow lupin Extract I.

Plasmid DNA of pATY2T7 and pATY2T7 scripts were incubated for $1.5 \mathrm{~h}$ with yellow lupin Extract I, purified on $8 \%$ PAGE/8 M urea and analysed for the presence of $\Psi 35$ after RNase T2 digestion by two-dimensional chromatography on cellulose thin-layer plates as described in Materials and Methods. (A) Autoradiogram of cellulose TLC plate obtained after chromatography of RNase T2 hydrolysate of intron-containing pre-tRNA ${ }^{\text {Tyr }}$. The efficiency of $\Psi 35$ formation was 0.8 mole of pseudouridine per one mole of pre-tRNA ${ }^{\text {Tyr }}$. (B) Autoradiogram of cellulose TLC plate obtained after chromatography of RNase T2 hydrolysate of intron-less pre-tRNA ${ }^{\text {Tyr }}$. The lack of the intron inhibited $\Psi 35$ formation.

$\mathbf{A}$

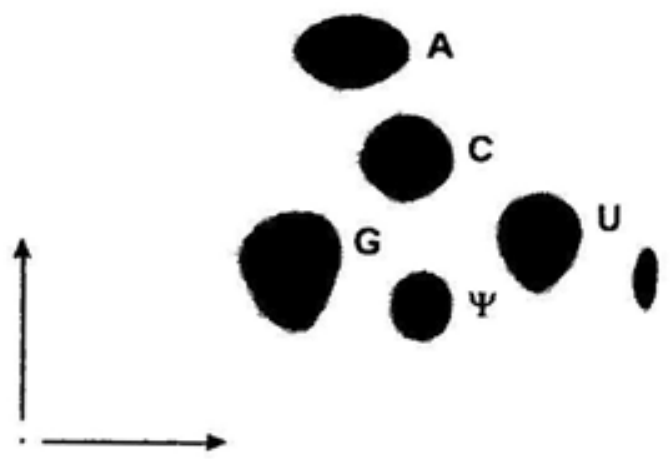

B

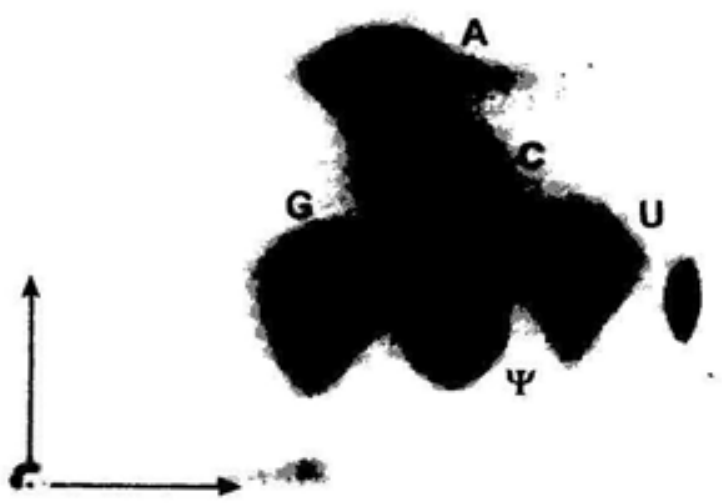

Figure 3. Pseudouridine 55 synthesis in yellow lupin Extract $\mathbf{I}$.

Plasmid DNA of pATY2T7U40 and pATY2T7DI were transcribed using T7 DNA polymerase and $\left[\alpha-{ }^{32} \mathrm{P}\right] \mathrm{CTP}$. The transcripts were incubated for $1.5 \mathrm{~h}$ with yellow lupin Extract I, purified on $8 \%$ PAGE/8 M urea and analysed for the presence of $\Psi 55$ after RNase T2 digestion by two-dimensional chromatography on cellulose thin-layer plates as described in Materials and Methods. (A) Autoradiogram of cellulose TLC plate obtained after chromatography of RNase T2 hydrolysate of intron-containing pre-tRNA ${ }^{\mathrm{Tyr}} \mathrm{U} 40$. The efficiency of $\Psi 55$ formation was 1.0 mole of pseudouridine per one mole of pre-tRNA ${ }^{\text {Tyr }}$. (B) Autoradiogram of cellulose TLC plate obtained after chromatography of RNase T2 hydrolysate of intron-less pre-tRNA ${ }^{\text {Tyr }}$. The efficiency of pseudouridine 55 formation was 1.0 mole of $\Psi$ per one mole of pre-tRNA ${ }^{\text {Tyr. }}$. 


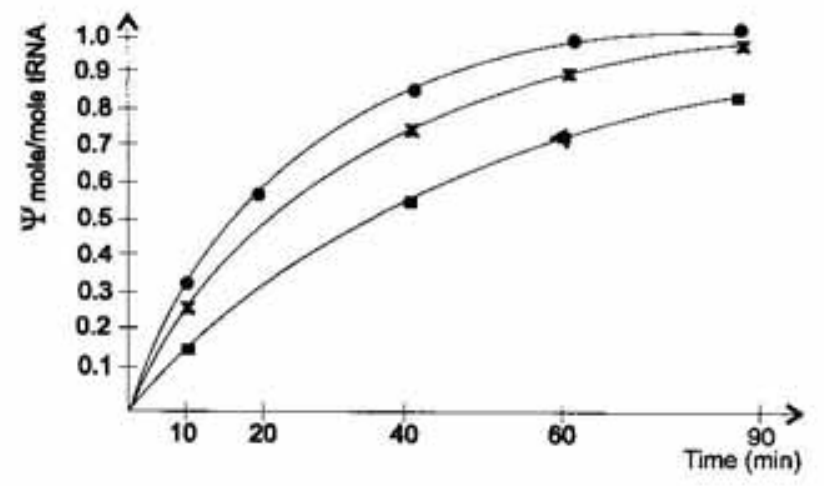

Figure 4. Kinetics of $\Psi 35$ and $\Psi 55$ formation in A. thaliana pre-tRNA ${ }^{\text {Tyr }}$ and its mutants.

About 2 pmole of appropriate ${ }^{32}$ P-labelled pre-tRNA ${ }^{\text {Tyr }}$ transcripts was incubated with lupin Extract I for the time indicated, and analysed for the relative amount of pseudouridine residues at positions 35 and 55 . $\mathbf{E}$, Wild type pre-tRNA ${ }^{\text {Tyr }}$ containing an intron, labelled with [ $\alpha$ ${ }^{32}$ PJATP - visualisation of $\Psi 35 ; \boldsymbol{*}$, pre-tRNA ${ }^{\text {Tyr }}$ containing an intron, U40 labelled with $\left[\alpha \cdot{ }^{32} \mathrm{P}\right] \mathrm{CTP}$ - visualisation of $\Psi_{55}$; , pre-tRNA ${ }^{\mathrm{Tyr}}$ without an intron, labelled with $\left[\alpha-{ }^{32} \mathrm{P}\right] \mathrm{CTP}-$ visualisation of $\Psi 55$.

thase activity in the lupin extract. As described above, analysis of the pre-tRNA ${ }^{\text {Tyr }}$ U40 containing an intron labelled with [ $\alpha$ ${ }^{32}$ PJCTP revealed full modification of U55 to $\Psi 55$ (Table 2, Fig. 2). The same results were obtained when pre-tRNA ${ }^{\text {Tyr }}$ without an intron, labelled with $\left[\alpha-{ }^{32} \mathrm{P}\right] \mathrm{CTP}$ was analysed (Fig. 3B). Our experiments show that the introduction of this modified nucleoside in lupin extract is insensitive to the presence or absence of an intron.

Kinetic data for $\Psi 35$ and $\Psi 55$ formation are shown in Fig. 4.

\section{DISCUSSION}

Our results show the presence in lupin extract of at least two enzymatic activities responsible for the pseudouridylation of U35 and U55 in plant pre-tRNA ${ }^{\text {Tyr }}$. We were not able to detect $\Psi 39$ synthase activity in either the lupin extracts (data for lupin Extract II are not shown). There are discrepancies in the lit- erature concerning the substrate requirements for formation of $\Psi 39$, which was found to be negatively intron-dependent in the case of tobacco pre-tRNA ${ }^{\text {Tyr }}$ [11] and introninsensitive in several other cases [3]. Since we did not observe the presence of $\Psi 39$ in pre$\mathrm{tRNA}^{\mathrm{Tyr}}$ containing an intron, there are three possibilities to explain this phenomenon: (i) lupin pseudouridine synthase 39 is negativelydependent on the presence of an intron, as it has been reported in the case of tobacco $\Psi 39$ synthase, (ii) conversion of C40 to U40 inhibited the reaction, (iii) there is no $\Psi 39$ synthase activity in the lupin seeds extract. We did not observe $\Psi 39$ in the intron-containing precursor but it is not present, either, in the intron-less molecule (conclusions are drawn from the fact that both molecules were pseudouridylated only up to one mole of $\Psi$ per mole of pre-tRNA and the mutant molecule of pre-tRNA ${ }^{\text {Tyr }} \mathrm{U} 40$ was not pseudouridylated at all when labelled with [ ${ }^{32}$ P]UT, and exhibited one mole of pseudouridine 55 when labelled with [ $\left.\left.{ }^{32} \mathrm{P}\right] \mathrm{CTP}\right)$. It seems to us unlikely that the transition of $\mathrm{C} 40$ to $\mathrm{U} 40$ would inhibit pseudouridylation at the uridine 39 : this position in different tRNAs is frequently pseudouridylated regardless of the nucleotide sequence environment [17]. We think that no $\Psi 39$ synthase is present in the lupin Extract I.

U35 is converted to $\Psi 35$ only in an introndependent manner, while pseudouridylation of U55 is insensitive to the presence or absence of an intron. It is unlikely that the two pseudouridines are introduced by the same enzyme. Pseudouridine synthase 35 requires the presence of an intron and a specific nucleotide sequence surrounding U35 to be modified [16]. Pseudouridine synthase 55 is an enzyme that modifies all cytoplasmic tRNAs at the conservative U55 in the TYC arm, in a structural environment completely different from that for U35 $[16,17]$. The idea of more than one pseudouridine synthase acting on both sites is supported by the results obtained by Samuelsson \& Olsson [18]. Using different mutants of yeast tRNA ${ }^{\text {Gly }}$ they have 
shown that pseudouridine activities corresponding to positions 13,32 and 55 in these tRNA substrates could all be separated chromatographically, indicating that there is a separate enzyme for each of these sites. Both $\Psi 35$ and $\Psi 55$ synthases seem to be present in the nucleus. $\Psi 35$ synthase requires the presence of an intron for its activity. Intron removal takes place at the nuclear envelope before mature tRNA ${ }^{\mathrm{Tyr}}$ leaves the nucleus. Pseudouridylation has to occur before splicing, also in the nucleus. The activity of $\Psi 55$ synthase is insensitive to the presence of an intron. Since it acts on substrates containing introns, it is possible that it is present also in the nucleus. The last idea is supported by the fact that yeast pre-tRNA ${ }^{\text {Tyr }}$, when injected into the Xenopus laevis oocyte nucleus, is fully pseudouridylated at the stage of an introncontaining precursor [19].

The preparation of the lupin extract exhibiting the activity of both $\Psi_{35}$ and $\Psi_{55}$ synthase is the first step in the purification and isolation of the two enzymes and their genes.

\section{R E F E R E N C ES}

1. Hopper, A.K. \& Martin, N.C. (1992) Processing of yeast cytoplasmic and mitochondrial tRNAs; in The Molecular and Cellular Biology of the Yeast Saccharomyces: Gene Expression. (Jones, E.W., Pringle, J.R. \& Broach, J.R., eds.) pp. 99-141, Cold Spring Harbor Laboratory Press, NY.

2. Peebles, C.L., Gegenheimer, P. \& Abelson, J. (1983) Precise excision of intervening sequences from precursor tRNAs by a membrane-associated yeast endonuclease. Cell 32, 525-536.

3. Grosjean, H., Szweykowska-Kulinska, Z., Motorin, X., Fasiolo, F. \& Simos, G. (1997) Intron dependent enzymatic formation of modified nucleotides in eukaryotic tRNAs: A review. Biochimie 79, 293-302.
4. Johnson, P.F. \& Abelson, J. (1983) The yeast $\mathrm{tRNA}^{\text {Tyr }}$ gene intron is essential for correct modification of its tRNA product. Nature 302 , 681-687.

5. Szweykowska-Kuliniska, Z., Senger, B., Keith, G., Fasiolo, F. \& Grosjean, H. (1994) Introndependent formation of pseudouridines in the anticodon of Saccharomyces cerevisiae minor tRNA ${ }^{\text {Ile }}$. EMBO J. 13, 4636-4644.

6. Grosjean, H., Droogmans, L., Giege, R. \& Uhlenbeck, O.C. (1990) Guanosine modifications in runoff transcripts of synthetic transfer $\mathrm{RNA}^{\text {Phe }}$ genes microinjected into Xenopus oocytes. Biochim. Biophys. Acta 1050, 267-273.

7. Strobel, M.C. \& Abelson, J. (1986) Effect of ir. tron mutations on processing and function of Saccharomyces cerevisiae SUP53 tRNA in vitro and in vivo. Mol. Cell Biol. 6, 2662-2673.

8. Melton, D.A., DeRobertis, E.M. \& Cortese, R. (1980) Order and intracellular location of the events involved in the maturation of spliced tRNA. Nature 284, 143-148.

9. Yukawa, Y., Sugita, M., Sugiura, M. (1997) Efficient in vitro transcription of plant nuclear tRNA(Ser) genes in a nuclear extract from tobacco cultured cells. Plant J. 12, 965-970.

10. Szweykowska-Kulińska, Z., Krajewski, J. \& Wypijewski, K. (1995) Mutations of Arabidopsis thaliana pre-tRNA ${ }^{\text {Tyr }}$ affecting pseudouridylation of U35. Biochim. Biophys. Acta 1264, 87-92.

11. Stange, N. \& Beier, H. (1987) A cell-free plant extract for accurate pre-tRNA processing, splicing and modification. EMBO J. 6, 2811-2818.

12. Guranowski, A. \& Pawełkiewicz, J. (1977) Adenosylhomocysteinase from yellow lupin seeds. Eur. J. Biochem. 80, 517-523.

13. Kunkel, T.A., Roberts, J.D. \& Zakour, R.A. (1987) Rapid and efficient site-specific mutagenesis without phenotypic selection. Methods Enzymol. 154, 367-382. 
14. Hattori, M. \& Sakaki, Y. (1986) Dideoxy sequencing method using denaturated plasmid templates. Anal. Biochem. 152, 232-238.

15. Nurse, K., Wrzesiński, J., Bakin, A., Lane, B.G. \& Ofengand, J. (1995) Purification, cloning and properties of the tRNA $\Psi 55$ synthase from Escherichia coli. RNA 1, 102-112.

16. Szweykowska-Kulińska, Z. \& Beier, H. (1992) Sequence and structure requirements for the biosynthesis of pseudouridine (I/35) in plant pre-tRNA $^{\text {Tyr }}$. EMBO J. 11, 1907-1912.
17. Sprinzl, M., Steegboren, C., Hubel, F. \& Steinberg, S. (1996) Compilation of tRNA sequences and of tRNA genes. Nucleic Acids Res. 24, 68-72.

18. Samuelsson, T. \& Olsson, M. (1990) Transfer RNA pseudouridine synthases in Saccharomyces cerevisiae. J. Biol. Chem. 265, 8782-8787.

19. Nishikura, K. \& De Robertis, E.M. (1981) RNA processing in microinjected Xenopus oocytes. Sequential addition of base modifications in a spliced transfer RNA. J. Mol. Biol. 145, 405-420. 